\title{
Pengaruh Digital dalam Presentasi Karya Arsitek pada Klien
}

Aria $\mathrm{ZADP}^{1}$, LMF Purwanto ${ }^{2}$

e-mail:ariazabdi@gmail.com ${ }^{1}$, psda@unika.ac.id ${ }^{2}$

Program Studi Doktor Arsitektur, UNIKA Soegijapranata Semarang ${ }^{1,2}$

\section{Abstrak}

Perkembangan teknologi digital beberapa dasawarsa terakhir secara signifikan mengubah cara arsitek bekerja. Revolusi digital dalam beberapa dekade terakhir ini memungkinkan kita untuk tidak hanya mengkonstruksi bangunan secara fisik, tetapi juga secara virtual. Presentasi merupakan tahap penting dalam sebuah pekerjaan arsitektur. Presentasi yang dilakukan arsitek adalah upaya untuk mengkomunikasikan sebuah informasi, yang berupa ide-ide dari sang arsitek. Klien sebagai penerima infomasi berasal dari berbagai kalangan dan latar belakang serta kemampuan spasial (spatial intelligence) yang berbeda. Oleh karena itu, berbagai upaya dilakukan agar presentasi yang dilakukan oleh arsitek lebih mudah diterima dan dipahami oleh klien. Perkembangan teknologi digital secara langsung dan tidak langsung mempengaruhi teknik presentasi arsitek kepada klien. Penelitian ini bertujuan mengetahui pengaruh perkembangan teknologi digital terhadap penyajian karya yang dilakukan arsitek terhadap klien. Di masa mendatang, penggunaan teknologi dalam penyajian karya arsitektur terus akan berkembang sesuai dengan perkembangan teknologi digital yang ada.

Kata Kunci : teknologi digital, presentasi arsitek, bim, virtual reality, augmented reality

\section{Abstract}

The development of digital technology in recent decades has significantly changed the way of architects work. The digital revolution in last decades has allowed us both construct buildings physically and virtually. Presentation is an important stage in an architectural work. The architect's presentation is an attempt to communicate the information, in the form of the architect's ideas. Clients as recipients of information come from various backgrounds and different spatial abilities (spatial intelligence). Therefore, various efforts were made to make presentations made by architects more easily accepted by clients. The development of the architect's presentation was influenced by developments in digital technology. Architecture is one of the areas where technology inventions are routinely used. The latest technologies are applied in various architectural software, one of which is the use of Virtual Reality and Augmented Reality technologies which were originally applied in game consoles and are now integrated in Building Information Modeling (BIM). In the future, the use of technology in presenting architectural works will continue to develop in accordance with existing digital technology developments.

Keywords : digital technology, architect presentation, bim, virtual reality, augmented reality 


\section{Pendahuluan}

Arsitek adalah salah satu profesi tertua dan berkembang seiring waktu. Arsitektur adalah salah satu bidang yang rutin menjadi pengguna temuan-temuan teknologi. Baik pemanfaatan temuan teknologi pada proses konstruksi maupun pada proses desain. Perkembangan komputasi digital ditandai dengan perkembangan teknologi semikonduktor pada kisaran tahun 1940. Sejak saat itu perkembangan teknologi digital terus mengalami peningkatan yang eksponensial. Dua dekade sejak ditemukannya komputer modern, arsitektur mulai memanfaatkan teknologi dalam proses desain, dengan dimulainya penggunaan komputer sebagai sarana bantu gambar atau Computer Aided Drawing (CAD) pada dekade 1960, hingga terus berkembang menjadi pemanfaatan BIM dalam dunia arsitektur maupun pemanfaatan realitas baru (Virtual Reality dan Augmented Reality) yang semula digunakan dalam konsol permainan tetapi kini digunakan dalam bidang konstruksi maupun perancangan.

Tujuan penelitian ini adalah untuk mengetahui pengaruh perkembangan teknologi digital dalam mendukung presentasi yang dilakukan arsitek terhadap klien. Sehingga diharapkan arsitek dapat lebih peka menghadapi perkembangan zaman dan memaksimalkan teknologi dan media yang ada untuk dapat mengkomunikasikan ide dan karyanya kepada klien dengan lebih baik.

\section{Desain dan Presentasi Arsitektur}

Desain (disegno) adalah upaya menciptakan bentukan fisik dari gagasan yang immaterial, untuk menghubungkan gagasan yang immaterial menjadi sebuah bentukan fisik, tidak terlepas dari proses menggambar dan berpikir. Anton Francesco Doni, seorang Tuscan terpelajar menyebutkan bahwa desain adalah industri intelektual yang melaksanakan pekerjaan dengan kekuatannya. Disegno dalam bahasa Italia berarti menggunakan baik kemampuan menggambar dan segenap kapasitas intelektual untuk membuat sebuah gambar (Foote, 2019). Alih bahasa disegno menjadi design dalam bahasa Inggris yang berarti rancangan atau gambar, mendegradasi nilai serta proses kerja yang mengikutinya. Desain seolah-olah menjadi pekerjaan yang menghasilkan produk gambar semata.

Menurut KBBI, presentasi berarti penyajian atau pertunjukan kepada orang-orang yang diundang (Kemdikbud, 2020). Dalam terjemahan bebas, presentasi berarti mengkomunikasikan sebuah informasi. Mempresentasikan karya arsitektur pada klien merupakan tahapan yang krusial dari sebuah proyek perancangan. Dalam presentasi, perancang mencoba mengkomunikasikan informasi yang berupa ide dan gagasan perancangan yang telah dibangun oleh perancang. Komunikasi merupakan hal penting dalam hubungan arsitek-klien, tanpa komunikasi yang baik tidak tercapai kesamaan visi mengenai proyek yang sedang dikerjakan (Murtagh et al., 2016).

Dalam dunia pendidikan arsitektur, kemampuan presentasi merupakan keterampilan swadidik dan proses tanpa batas yang harus terus dikembangkan setiap mahasiswa. Disebut sebagai proses tanpa batas karena perkembangan teknologi digital memicu presentasi arsitektur untuk turut berkembang. Kemampuan mempresentasikan karya melalui perangkat lunak arsitektur diasah melalui studio-studio perancangan dalam pendidikan arsitektur. Tetapi saat memasuki dunia 
Penaaruh Digital dalam Presentasi Karya Arsitek

praktisi, seringkali perangkat lunak yang pernah dipelajari saat menjadi peserta didik telah out-todate.

Presentasi arsitek ke klien membutuhkan interaksi dan komunikasi yang baik. Semakin kecil skala proyek, semakin intens interaksi antara arsitek dan klien (Murtagh et al., 2016). Untuk membentuk interaksi dan komunikasi yang baik dalam menyampaikan informasi berupa rancangan atau desain, diperlukan sarana yang mampu menjembatani pemikiran antara arsitek dan klien.

\section{Metode Penelitian}

Metode yang digunakan dalam penelitian ini adalah literature review pada penelitian terpublikasi dalam batasan waktu sesuai dengan perkembangan teknologi digital yang mempengaruhinya. Dari literatur akan dikelompokkan tipologi presentasi yang umum digunakan arsitek, dan perkembangan yang diakibatkan perkembangan teknologi digital yang ada.

\section{Hasil dan Pembahasan}

\subsection{Interaksi Arsitek - Klien}

Interaksi arsitek dan klien diharapkan berjalan dengan baik, karena arsitek bekerja pada wilayah semi-privat bahkan privat dari klien. Semakin kecil besaran suatu proyek, semakin tinggi intensitas interaksi antara perancang dengan klien. Arsitek diupayakan untuk dapat menangkap 90\% keinginan klien dalam suatu proyek (Murtagh et al., 2016).

Tugas arsitek adalah mewujudkan keinginan dan kebutuhan klien dalam sebuah rancangan bangunan. Keinginan dan kebutuhan klien adalah dasar atau pijakan arsitek dalam mengawali sebuah perancangan. Oleh karena itu, interaksi dan komunikasi antara arsitek dan klien seyogyanya dapat berlangsung sebaik mungkin. Demikian juga informasi yang dipresentasikan arsitek sebagai umpan balik dari keinginan dan kebutuhan klien harus dapat diterima dan dipahami oleh klien (Taleb et al., 2017). Oleh karena itu, interaksi dan komunikasi antara arsitek dengan klien merupakan hal yang wajib diperhatikan dalam sebuah proyek perancangan.

Interaksi antara arsitek dan klien merupakan sebuah proses diskusi dan berbagi pengalaman antara arsitek dan klien dengan latar belakang masing-masing yang berbeda. Sehingga jika interaksi dan komunikasi dapat berlangsung dengan baik akan dapat mencapai tujuan yang sama (McDonnell \& Lloyd, 2014).

Dalam proses komunikasi antara arsitek dengan klien, ambiguitas atau ketidakjelasan merupakan permasalahan serius yang dapat mendorong kesalahpahaman dan merusak komunikasi. Kejelasan (clarity) dalam komunikasi arsitek dan klien menjadi hal yang sangat penting. Dalam proses merancang, komunikasi antara arsitek dengan klien merupakan proses akuisisi pengetahuan sekaligus negosiasi, sehingga diperlukan keterampilan teknis maupun sosial (Norouzi et al., 2015). Penggunaan media dan teknologi dalam presentasi merupakan salah satu keterampilan teknis yang dapat mendukung proses interaksi dan komunikasi berjalan dengan baik.

Interaksi dan komunikasi antara arsitek dan klien yang berjalan dengan baik, tidak hanya berguna dalam menyelesaikan proses desain maupun konstruksi sebuah proyek, tetapi juga menjaga reputasi arsitek dan strategi bisnis jangka panjang bagi arsitek (Ivory, 2004).

78 | Volume 4 Nomor 2 Februari 2021 


\subsection{Pengaruh Digital pada Tipologi Presentasi Arsitek}

Dalam realita, proses merancang hampir mustahil dilakukan tanpa memvisualisasikan ide, imajinasi maupun gagasan melalui sebuah gambar, apapun medianya (Stein $\varnothing, 2018$ ). Perbedaaan penggunaan media yang digunakan arsitek dalam mempresentasikan karyanya pada klien berpengaruh pada performa visual dan persepsi yang diterima oleh klien (Yavuz \& BALA, 2015).

\subsubsection{Sketsa dan Evolusinya}

Selama berabad-abad sebelum teknologi digital ditemukan, sketsa menjadi alat utama komunikasi arsitek kepada klien. Sketsa merupakan upaya untuk menuangkan gagasan maupun imajinasi pada sebuah bidang untuk dapat disaksikan oleh orang lain (Kim, 2010). Sebuah gambar perspektif jika digambar secara benar dan memiliki skala yang tepat, akan dapat merepresentasikan sebuah geometri bangunan maupun benda lain, sehingga penampilannya akan dapat dinilai sebelum bangunan tersebut didirikan. Sehingga penting bagi pensketsa untuk membuat representasi yang akurat (Roberts, 1916). Sketsa merupakan artefak yang fundamental dalam sebuah proses desain (Perrone et al., 2006). Zaha Hadid dalam awal karirnya menggunakan sketsa sebagai sarana penyajian karya (Luscombe, 2020). Sketsa adalah ekspresi desain yang paling ringkas, cepat, murah dan intuitif (Y. Li \& Ning, 2017).

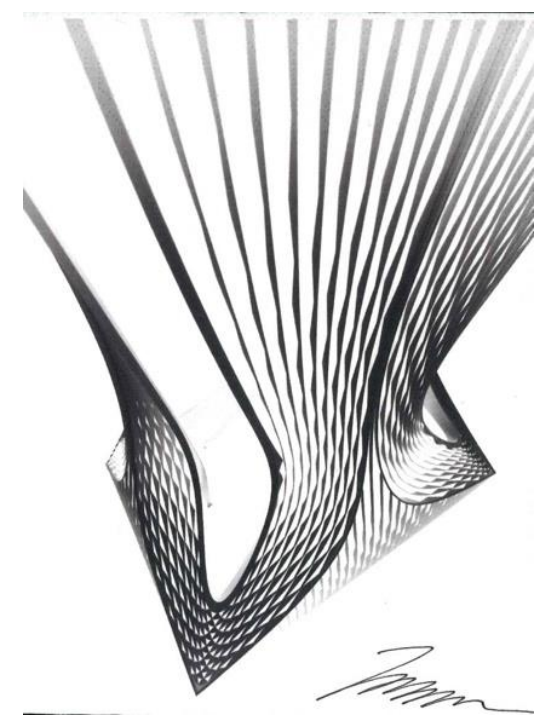

Gambar-1. Sketsa Zaha Hadid (Sumber: New School of Design, 2019)

Nikken Sekkei, Ltd adalah biro arsitektur multinasional yang konsisten menggunakan sketsa dalam mempresentasikan beberapa sudut dari tiap proyek yang dikerjakannya. Pentingnya sketsa dalam penyajian karya arsitektur membuat perkembangan digital yang masif tidak mendegradasi sketsa, tetapi justru mendigitalisasi sketsa agar dapat dilakukan dengan lebih mudah dan pratis. 


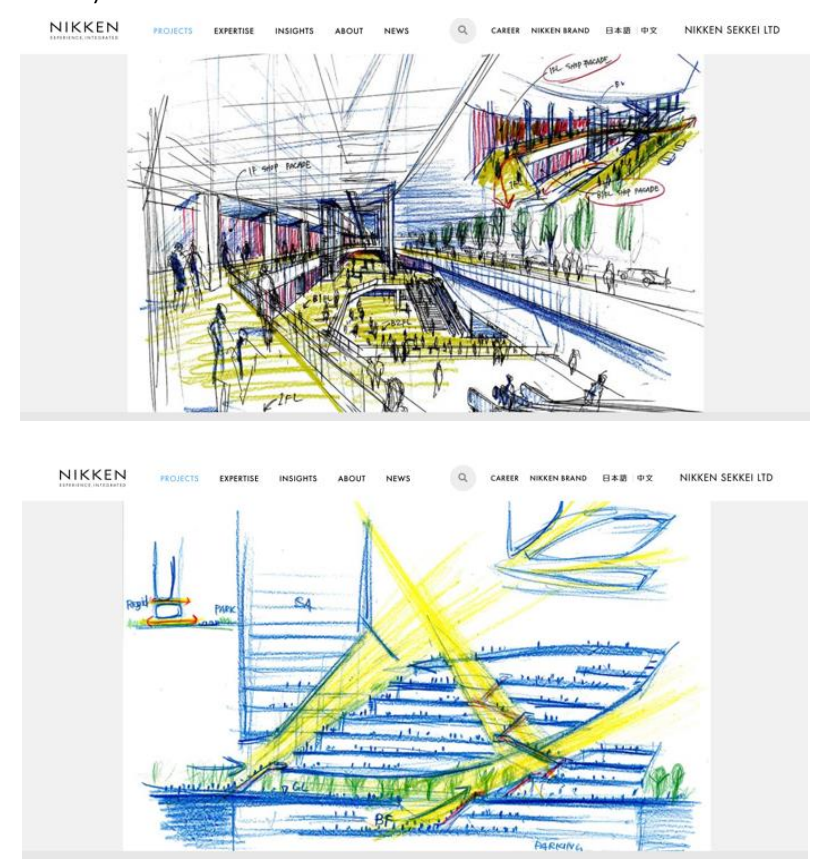

Gambar-2. Presentasi Arsitektur Nikken Sekkei, Ltd - Jepang (Sumber: Nikken.co.jp, 2020)

Beberapa perangkat lunak dikembangkan oleh pengembang aplikasi seperti Autodesk yang mengembangkan SketchBook, WeTransfer mengembangkan aplikasi Paper, juga beberapa perusahaan yang membuat aplikasi sketsa sebagai produk utama seperti Morpholio dan Magicplan. Berbagai pengembangan komputasi grafis dilakukan untuk membuat pengalaman sketsa digital semirip mungkin dengan sketsa konvensional, tetapi memiliki nilai tambah (L. Li et al., 2020). Dukungan terhadap sketsa tidak hanya dilakukan oleh pengembang perangkat lunak tetapi juga manufaktur perangkat keras seperti Microsoft, Apple dan Wacom yang mengembangkan graphic tablet dan pensil digital.
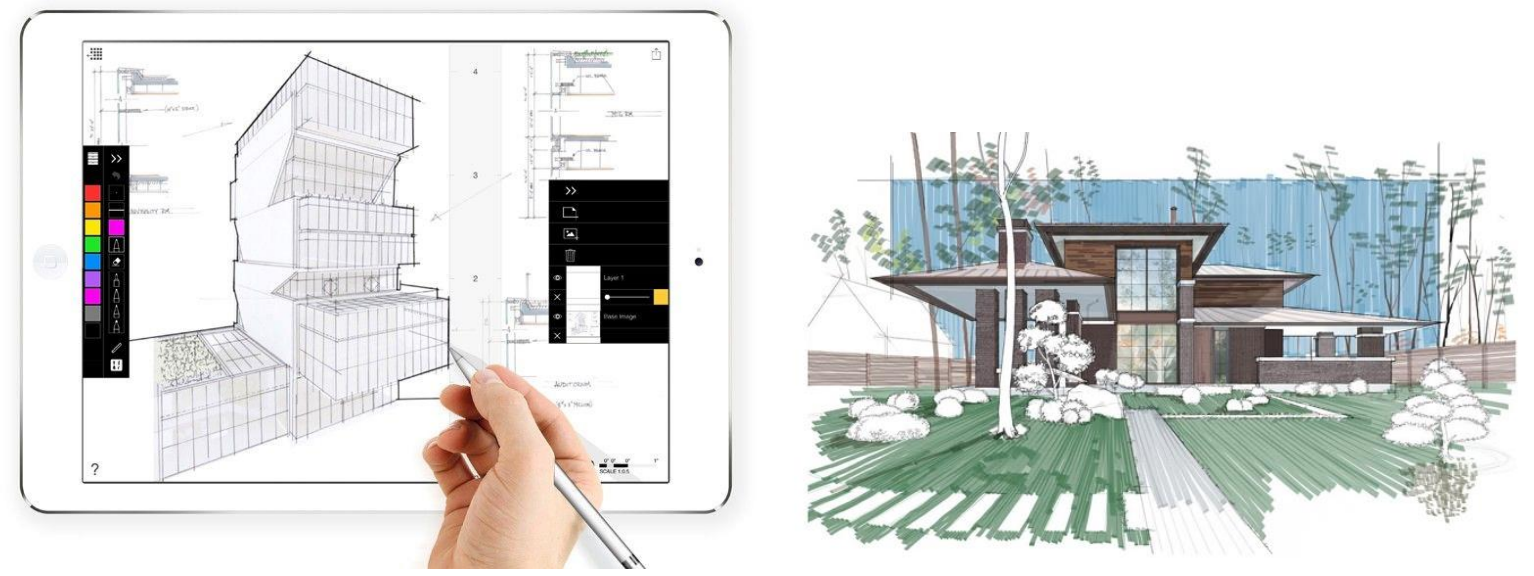

Gambar-3. Sketsa digital dengan Morpholio dan Sketchbook (Sumber: Morpholio, 2020; Autodesk, 2020)

\subsubsection{Gambar Kerja Arsitektural}

Gambar kerja merupakan perkembangan dari sketsa untuk presentasi yang lebih detail dan terstandar. Gambar kerja merupakan lompatan besar dari sketsa, dimana gambar dapat memuat informasi teknis dengan lengkap dan akurat. Sampai dengan abad ke-13, perancangan dilakukan 
dalam skala 1:1 dengan menggambar rancangan pada tanah (Seelow, 2017). Dengan gambar kerja, rancangan dapat dipresentasikan secara skalatis dan detail.

Dengan penemuan komputer dan perkembangan teknologi digital, gambar kerja arsitektural kini diproduksi dengan CAD (Computer-Aided Drawing) dan digunakan hingga kini untuk menjadi pedoman teknis bagi klien maupun konstruktor.

\subsubsection{Maket Model 3D}

Diantara berbagi media yang digunakan untuk presentasi arsitektural, pemahaman pengguna terhadap maket model adalah yang paling signifikan, karena maket model menjembatani gambar, antara abstrak dan realitas (Seelow, 2017). Maket model 3D pertama yang ada dalam catatan tertulis adalah maket model lilin dari gereja Saint Germain di Auxerre yang dibuat pada abad ke-9. Karena kelebihannya untuk lebih mudah dipahami secara spasial dibandingkan dengan sketsa maupun gambar 2D, di tengah disrupsi digital, maket model tetap dikembangkan dengan prosesproses pembuatan yang dimudahkan.

CAM (Computer-Aided Manufacturing) atau sering disebut juga Computer-Aided Modelling atau Computer-Aided Machining pada dasarnya merupakan pengembangan dari CAD. CAM adalah penggunaan komputer atau aplikasi untuk mengendalikan / mengontrol sebuah mesin atau alat kerja kaitannya dengan proses manufaktur. Banyak dari aplikasi CAD yang dikembangkan menjadi CAM, agar aplikasi tersebut dapat terhubung langsung dengan mesin, misal AutoCAD, Cura, TinkerCAD, MeshLAB, Rhino, FreeCAD, CATIA, Creo dan sebagainya. Aplikasi CAM terhubung dengan berbagai mesin CNC (Computerized Numerical Control) sesuai dengan kebutuhan, baik untuk membuat presentasi arsitektural maupun sebagai mesin fabrikasi (Carreiro \& Pinto, 2013).

Sebagai sarana presentasi arsitektur, CAM dihubungkan dengan 3D printer untuk membuat model 3D dari model virtual yang telah dibuat.

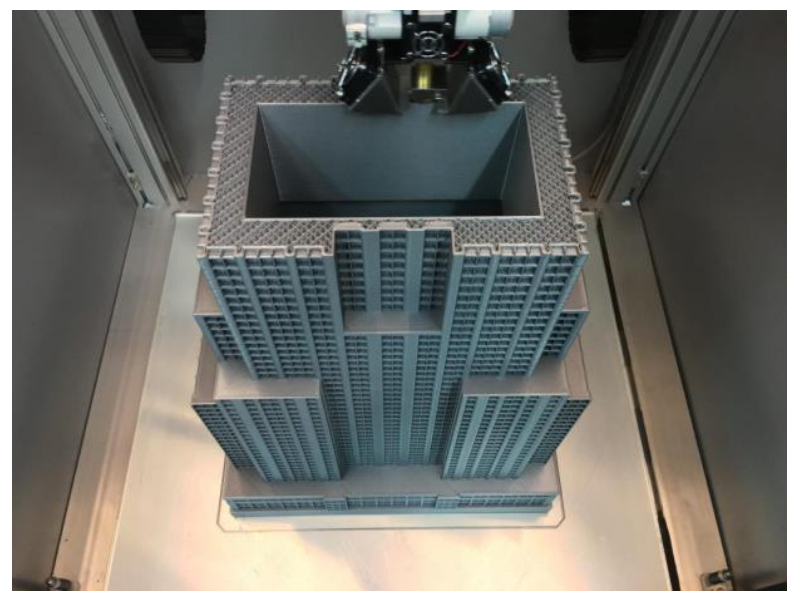

Gambar-4. 3D Printing (Sumber: 3dprintingindustry.com, 2020)

\subsubsection{CAD dan Evolusinya}

Penggunaan CAD (Computer Aided Drawing) merupakan kemampuan dasar yang wajib dimiliki arsitek untuk dapat berkompetisi dewasa ini (Dare-Abel et al., 2016). Penggunaan komputer sebagai 
Penaaruh Digital dalam Presentasi Karya Arsitek

alat bantu gambar dimulai setelah dikembangkannya SketchPad, sebuah aplikasi yang digunakan untuk merancang komponen pada industri otomotif. SketchPad menjadi cikal bakal perkembangan aplikasi CAD. Lini masa perkembangan penggunaan komputer sebagai alat gambar sebagai berikut:

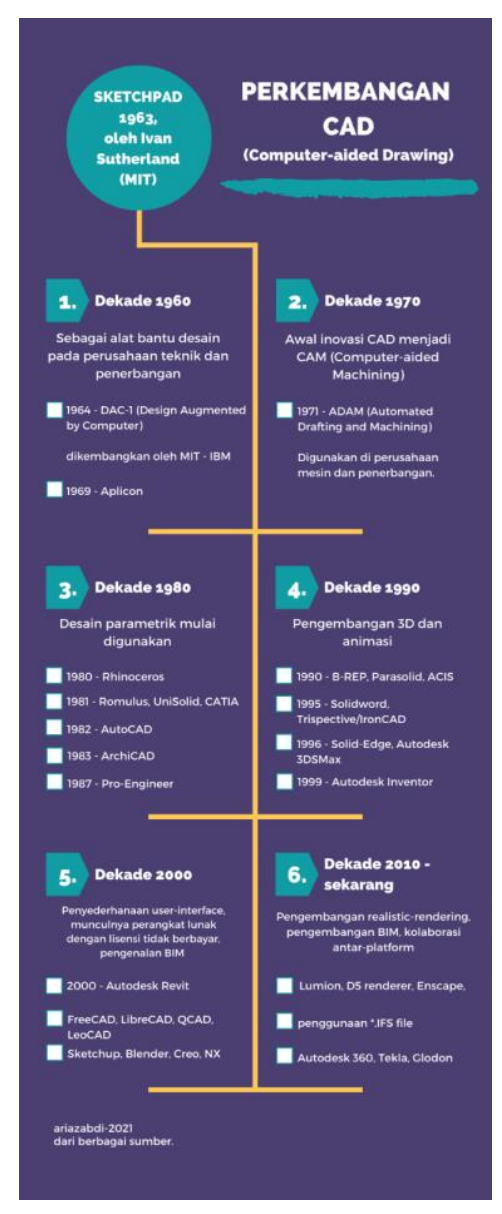

Gambar-5. Infografis perkembangan CAD (Sumber: infografis penulis)

Dalam perkembangannya, di satu waktu CAD tidak hanya memiliki kemampuan memproduksi gambar 2D, tetapi juga dapat memproduksi 3D bahkan gambar $360^{\circ}$ hingga gambar bergerak (animasi) yang realistik secara paralel (Carreiro \& Pinto, 2013). Bahkan kebanyakan perangkat lunak kini mengadopsi sistem live render, dimana proses render menjadi instan, sehingga pengubahan pengaturan dan desain secara langsung muncul pada output. Hal ini mempersingkat waktu dan dapat membantu ketika ada perubahan instan pada saat presentasi arsitek ke klien. Beberapa perangkat lunak arsitektur yang menggunakan live render adalah Enscape, Lumion, d5renderer, Twinmotion, dan sebagainya. 


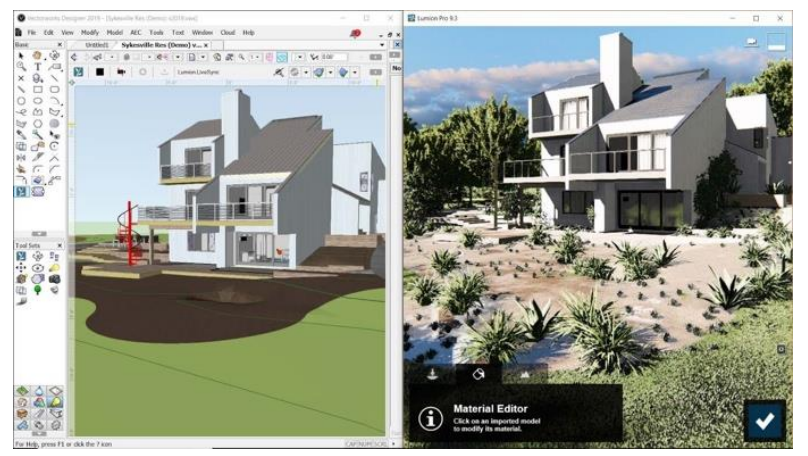

Gambar-6. Live renderer pada Lumion (Sumber: Lumion,2020)

Dengan berkembangnya teknologi digital dan temuan-temuan di bidang manajemen konstruksi, CAD dikembangkan menjadi Building Information Modelling (BIM). BIM adalah serangkaian proses yang berdasar model 3D, yang memberikan bidang arsitektur, keteknikan, maupun konstruksi agar dapat merencanakan, merancang, mendirikan dan mengelola sebuah proyek dengan lebih efisien. BIM merupakan sebuah platform kolaborasi antar bebagai pemegang kepentingan (stakeholder) dalam sebuah proyek, termasuk di dalamnya antara arsitek dan klien. Penerapan BIM memiliki beberapa tujuan, diantaranya adalah: (Direktorat Jenderal Cipta Karya, 2018)

Meningkatkan efisiensi dan akurasi.

Proses desain dan konstruksi menjadi lebih ramping dan transparan.

Akurasi dalam perhitungan.

Kolaborasi yang lebih baik antara stakeholder dalam desain dan konstruksi sehingga kesalahan dapat dihindari mulai dari proses perencanaan hingga pelaksanaan.

Waktu pelaksanaan dapat dipercepat karena efisiensi yang dicapai.

\section{$\underline{3 \text { level BIM }}$}

Untuk mempermudah pemahaman tentang BIM, ada beberapa level BIM yang menunjukkan perbedaan dan peningkatan (seperti ditunjukan pada Gambar.7), yaitu:

(Zeynep Onur \& Nouban, 2019)

- $\quad$ BIM level-0, adalah penggunaan komputer sebagai alat bantu untuk membuat gambar $2 \mathrm{D}$, beberapa perangkat lunak yang termasuk di dalamnya adalah AutoCAD dan Draftsight.

- $\quad$ BIM level-1, adalah proses penggunaan komputer untuk modelling 2D dan 3D, tetapi terpisah antara satu dengan yang lain. BIM level-1 sering disebutkan sebagai transisi antara CAD dan BIM. Perangkat lunak arsitektur yang termasuk di dalamnya adalah AutoCAD Architecture, TurboCAD, SketchUp, dan sebagainya.

- $\quad$ BIM level-2 adalah proses kolaborasi seluruh data, gambar 3D yang dihasilkan sudah berisikan informasi dan entitas yang lengkap sehingga dapat digunakan untuk berbagai perhitungan berikutnya, baik mengenai biaya, kekuatan struktur, performa bangunan dan sebagainya. Beberapa perangkat lunak arsitektur yang dikualifikasikan dalam BIM level-2 adalah Autodesk Revit, ArchiCAD, Vectorwork Architect, dan Allplan Architecture. 
BIM level-3 hingga saat ini belum sepenuhnya terdefinisikan dan terus dikembangkan, visi dari BIM level-3 adalah interoperabilitas data, sehingga data yang sama dapat digunakan oleh berbagai disiplin, baik arsitektur, struktur, manajemen konstruksi, dan pihak-pihak yang berkepentingan. Sampai dengan saat ini, beberapa format file dikembangkan untuk mendukung interoperabilitas data, seperti file IFC (Industry Foundation Classes) yang menjembatani beberapa perangkat lunak BIM arsitektur dan struktur atau manajemen konstruksi (Tekla, Glodon, CSI dan sebagainya).

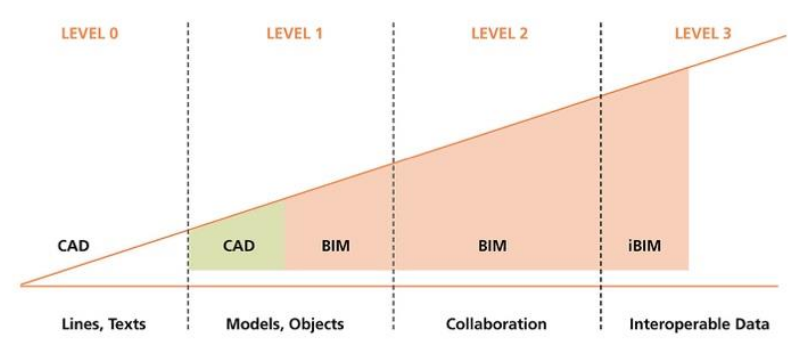

Gambar-7. Level pada BIM (Sumber: Stroma Certification, 2020)

Dengan menggunakan BIM (level-2), presentasi dari perancang berlangsung secara terus menerus karena progress dari perancang dapat terus dipantau oleh klien, sehingga interaksi dapat terus dilakukan secara virtual. Hal ini dimungkinkan dengan penggunaan sistem cloud sebagai sarana penyimpan data, sehingga satu data yang sama dapat diakses oleh berbagai pihak yang memiliki kepentingan.

\subsubsection{Virtual \& Augmented Reality}

Virtual Reality (VR) merupakan teknologi yang mulai dikenal luas. Teknologi ini sangat imersif (nyata) dan mencoba memperdaya indera untuk berpikir ada di lingkungan atau dunia yang lain, terpisah dari dunia nyata. Dengan menggunakan head-mounted display (HMD) dan headset, kita akan mengalami dunia citra dan suara yang dihasilkan komputer di mana kita dapat memanipulasi objek dan bergerak menggunakan pengontrol haptik yang dikoneksikan ke konsol atau PC.

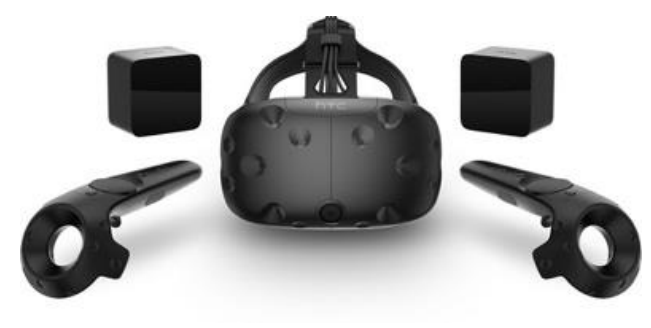

Gambar-8. Perangkat VR (Sumber: HTC Vive, 2020)

Beberapa perangkat lunak arsitektur yang mendukung presentasi atau penyajian menggunakan VR adalah Autodesk Live, Enscape, Fuzor, dan Unreal Engine (originated game engine). Melalui pengalaman dengan VR, klien dapat merasakan suasana atau atmosfer ruang dari desain yang diciptakan, terutama yang berkaitan dengan visual, seperti skala, warna dan pencahayaan. Penggunaan VR dapat memperkaya pengalaman meruang (spatial experiences) penggunanya, 
terkait dengan skala ruang, kualitas visual hingga pencahayaan (Sapto Pamungkas et al., 2018). Penggunaan VR juga dapat mempermudah pemahaman bagi penggunanya akan struktur dan konstruksi bangunan (Abdelhameed, 2013; Chan, 2015).

Augmented Reality (AR) adalah teknologi yang melapiskan informasi digital pada elemen dunia nyata. Augmented reality menjaga dunia nyata tetap menjadi sentral tetapi meningkatkannya dengan detail digital lainnya, melapisi dengan lapisan persepsi baru, dan melengkapi realitas atau lingkungan.

Penggunaan AR paling umum dalam presentasi arsitektural saat ini adalah untuk menggantikan maket model 3D dengan menggunakan perangkat mobile. Selain itu AR juga dapat digunakan untuk memindahkan model virtual pada lahan atau ruang eksisting dengan skala penuh menggunakan perangkat mobile.

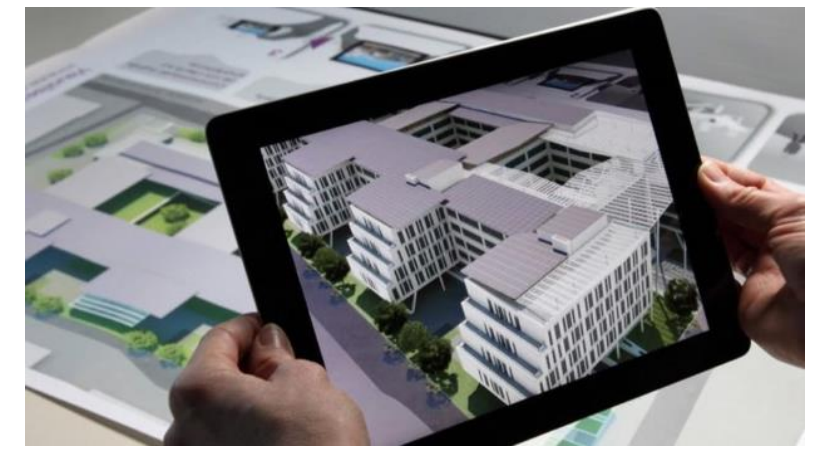

Gambar-9. Maket Model Virtual dengan AR (Sumber: Somic.com, 2020)

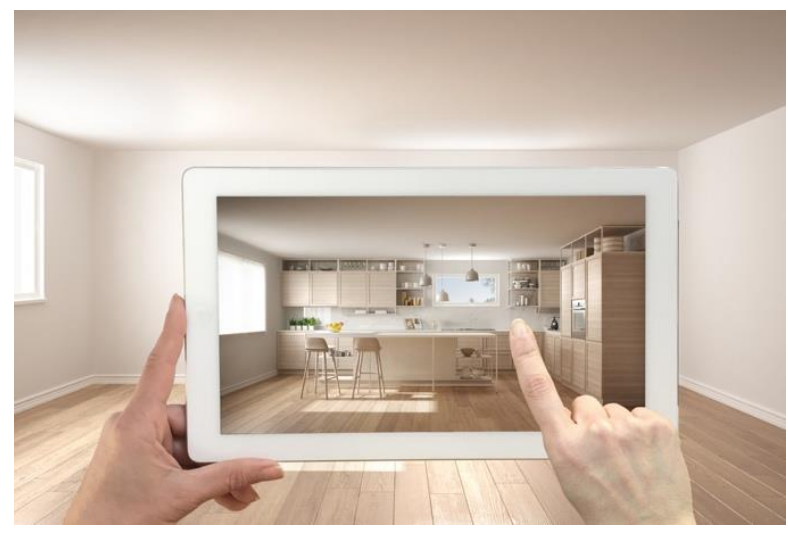

Gambar-10. Visualisasi ruang dengan AR (Sumber: Lamresearch, 2020)

Pada beberapa firma arsitektur besar, AR dan VR mulai dipergunakan dalam berbagai keperluan secara holistik, mulai dari tahapan pelatihan staff (training), perancangan, manajemen, konstruksi hingga pertemuan dengan klien (Davila Delgado et al., 2020).

Presentasi yang dilakukan arsitek harus berpusat pada klien, dengan mempertimbangkan karakter dan kemampuan klien, hal yang harus dipertimbangkan adalah bagaimana informasi tersampaikan sepenuhnya kepada klien (Stouffs \& Tuncer, 2014). Dengan perkembangan teknologi yang membawa presentasi arsitek ke arah yang lebih mutakhir, sebagian klien tetap menginginkan presentasi desain dilakukan sesuai dengan keinginan klien (Murtagh et al., 2016). 


\section{Kesimpulan}

Metode dan teknik presentasi arsitektural berkembang seiring dengan teknologi digital. Walaupun pengembangan teknik presentasi arsitektur masif di teknologi live-realistic rendering, virtual reality dan augmented reality, teknik presentasi sketsa dan maket model merupakan teknik yang fundamental di dunia arsitektur dan tetap mendapatkan dukungan dari perkembangan teknologi digital. Pemilihan metode presentasi berpusat pada klien dan disesuaikan dengan karakter klien, dengan tujuan informasi dari arsitek dapat diterima dengan baik oleh klien. Arsitek yang tanggap dan beradaptasi terhadap perkembangan teknologi digital akan menjadi nilai tambah, baik dalam proses perancangan maupun penyajian karya terhadap klien.

\section{Daftar Pustaka}

Abdelhameed, W. A. (2013). Virtual reality use in architectural design studios: A case of studying structure and construction. Procedia Computer Science, 25(December 2013), 220-230. https://doi.org/10.1016/j.procs.2013.11.027

Carreiro, M., \& Pinto, P. (2013). The evolution of representation in architecture. Future Traditions: Rethinking Traditions and Envisioning the Future in Architecture Trough the Use of Digital Technologies, 27-37.

Chan, C. (2015). Virtual Reality in Architectural Design. lowa State University.

Dare-Abel, O., Uwakonye, O., \& Opoko, A. (2016). the Effect of Cad on Architecture Students' Creativity and Enthusiasm. INTED2016 Proceedings, 1(March), 8530-8536. https://doi.org/10.21125/inted.2016.0984

Davila Delgado, J. M., Oyedele, L., Demian, P., \& Beach, T. (2020). A research agenda for augmented and virtual reality in architecture, engineering and construction. Advanced Engineering Informatics, 45(December 2019), 101122. https://doi.org/10.1016/j.aei.2020.101122

Direktorat Jenderal Cipta Karya. (2018). Kebijakan Dan Roadmap Penerapan Building Information Modeling (Bim) Mendukung Konstruksi Digital Indonesia. November.

Foote, J. (2019). Book Review: Paul Emmons. Drawing Imagining Building: Embodiment in Architectural Design Practices. Montreal Architectural Review, 2, 5-9.

Ivory, C. (2004). Client, user and architect interactions in construction: implications for analysing innovative outcomes from user-producer interactions in projects.

https://doi.org/https://doi.org/10.1080/0953732042000295801

Kemdikbud. (2020). Kamus Besar Bahasa Indonesia. kbbi.kemdikbud.go.id

Kim, I.-S. (2010). Drawing My Office: A Study on Architectural Representation of Time. January, 162. http://etheses.whiterose.ac.uk/id/eprint/14965

Li, L., Zou, C., Zheng, Y., Su, Q., Fu, H., \& Tai, C.-L. (2020). Sketch-R2CNN: An RNN-Rasterization-CNN Architecture for Vector Sketch Recognition. IEEE Transactions on Visualization and Computer Graphics, 2626(c), 1-1. https://doi.org/10.1109/tvcg.2020.2987626

$\mathrm{Li}, \mathrm{Y} .$, \& Ning, W. (2017). The Role of Sketch in Architecture Design. IOP Conference Series: Materials Science and Engineering, 216(1). https://doi.org/10.1088/1757-899X/216/1/012060

Luscombe, D. (2020). Zaha Hadid's notebooks: the sketch in architecture. Journal of Architecture, 25(3), 
252-275. https://doi.org/10.1080/13602365.2020.1758951

McDonnell, J., \& Lloyd, P. (2014). Beyond specification: A study of architect and client interaction. Design Studies, 35(4), 327-352. https://doi.org/10.1016/j.destud.2014.01.003

Murtagh, N., Roberts, A., \& Hitchings, R. (2016). Architect-Client Interactions Research Project. 1-10.

Norouzi, N., Shabak, M., Embi, M. R. Bin, \& Khan, T. H. (2015). The Architect, the Client and Effective Communication in Architectural Design Practice. Procedia - Social and Behavioral Sciences, 172, 635642. https://doi.org/10.1016/j.sbspro.2015.01.413

Perrone, R., Lima, A. G., \& Florio, W. (2006). The sketches and the design process in architecture. Working Papers in Art \& Design, January.

Roberts, H. W. (1916). Architectural Sketching \& Drawing in Perspective.

Sapto Pamungkas, L., Meytasari, C., \& Trieddiantoro, H. (2018). Virtual Reality As A Spatial Experience For Architecture Design: A Study of Effectiveness for Architecture Students. SHS Web of Conferences, 41, 05005. https://doi.org/10.1051/shsconf/20184105005

Seelow, A. M. (2017). Models as a Medium in Architecture. December, 1-10. https://doi.org/10.20944/preprints201712.0071.v1

Stein $\varnothing$, N. (2018). Architectural Drawing: Notation, Reflection, Communication and Presentation. Process and Practice Across Design Disciplines, 2018, 129-135.

https://www.forskningsdatabasen.dk/en/catalog/2394243651

Stouffs, R., \& Tuncer, B. (2014). Information Architecture : Presentation and Representation Information Architecture : Presentation and Representation. April 1997.

Taleb, H., Ismail, S., Wahab, M. H., \& Rani, W. N. M. W. M. (2017). Communication management between architects and clients. AIP Conference Proceedings, 1891(October). https://doi.org/10.1063/1.5005469

Yavuz, A., \& BALA, H. (2015). The Relation between Visual Presantation and Architectural Design Products. Online Journal of Art and Design, 3(2), 6-8.

Zeynep Onur, A., \& Nouban, F. (2019). Software in the architectural presentation and design of buildings: State-of-the-art. International Journal of Innovative Technology and Exploring Engineering, 8(10), 2723-2729. https://doi.org/10.35940/ijitee.J9486.0881019 